\title{
O processo de definição de sociofísica e econofísica como campos de estudo
}

\section{The process of defining sociophysics and econophysics as fields of study}

\author{
Leonardo Luiz e Castro ${ }^{1}$, Fábio Luís de Oliveira Paula ${ }^{1}$ \\ ${ }^{1}$ Instituto de Física - Universidade de Brasília
}

\begin{abstract}
Resumo
A adaptação de metodologias das ciências físicas ao estudo de fenômenos sociais e econômicos deu origem à ideia de sociofísica e econofísica como campos de estudo. A ideia do estudo do sociedade como uma "física social" já estava presente no ideário de precursores do sociologia como Comte e Quéletet, mas essa abordagem é considerada superada ou mesmo perigosa por grande parte dos cientistas sociais, o que influencia sua opinião sobre a sociofísica, embora esta também possa ser considerada como um fenômeno distinto das ideias originais de física social. Outras objeções comuns à sociofísica relacionam-se à maior complexidade dos fenômenos sociais em relação aos fenômenos físicos e ao fato de que o próprio observador seja parte do objeto estudo nos estudos sociais. É uma ideia recorrente que a complexidade do ser humano impossibilita a abordagem por meio de equações matemáticas. Essa ideia não nos parece totalmente justificada porque, nos estudos de sociofísica e econofísica que analisamos, os modelos matemáticos não aparecem como as únicas ferramentas utilizadas, mas como recursos adicionais de análise, havendo referências a observações e dados vindos de estudos sociológicos, psicológicos e econômicos. Não é razoável que o estudo de sistemas mais complexos seja prejudicado pela inclusão de mais recursos e possibilidades metodológicas. Objeções semelhantes também são feitas à econofísica, que também pode ser entendida como uma ciência social, mas o maior conflito entre econofísicos e economistas refere-se ao fato de que esses profissionais frequentemente usam os mesmos conceitos e metodologias, de modo que seja difícil definir fronteiras entre seus campos de atuação. De forma geral, a abordagem da econofísica não é estranha aos economistas, que estão mais habituados a análises estatísticas e modelos matemáticos. A maioria dos estudos de econofísica e sociofísica poderia ser também classificada em outros campos de estudo: economia financeira, sociologia matemática, sistemas dinâmicos, dinâmica de sistemas, teoria dos jogos, teoria da complexidade etc. A teoria da complexidade, sob a denominação "sistemas complexos", tem sido citada como uma área destacadamente multidisciplinar, oferecendo uma oportunidade de maior interação de econofísicos e sociofísicos com profissionais de outras áreas.
\end{abstract}

Palavras-chave: Econofísica. Sociofísica. Sistemas complexos. 
The adaptation of physical science methodologies to the study of social and economic phenomena gave rise to the idea of sociophysics and economophysics as fields of study. The idea of studying society as a "social physics" was already present in the ideas of precursors of sociology such as Comte and Quéletet, but this approach is considered outdated or even dangerous by many social scientists, and this ideia affects their opinion about sociophysics, even though sociophysics might be considered as a phenomenon distinct from the original ideas of social physics. Other objections common to sociophysics relate to the greater complexity of social phenomena in relation to physical phenomena and to the fact that the observer himself is part of the studied objects of social studies. It is a recurring idea that the complexity of human being prevent its study through mathematical equations. This idea does not seem fully justified to us because, in the sociophysical and econophysical studies that we analyzed, mathematical models do not appear as the only tools, but as additional analytical resources, which does not preclude the reference to observations and data from sociological, psychological and economic studies. . It is not reasonable to think that the study of a more complex system is hampered by the inclusion of more analysis tools and methodological possibilities. Similar objections are also made to econophysics, which can also be understood as a social science, but the biggest conflict between econophysicists and economists concerns the fact that these professionals often use the same concepts and methodologies, so that it is difficult to define boundaries between their fields of activity. In general, the econophysics approach is familiar to economists, who are more accustomed to statistical analysis and mathematical models. Most econophysics and sociophysics studies could equally well be classified in other fields of study: financial economics, mathematical sociology, dynamic systems, system dynamics, game theory, complexity theory, etc. Complexity theory, under the name "complex systems", has been cited as an eminently multidisciplinary area, offering an opportunity for greater interaction between economophysicists and sociophysicists with professionals from other areas.

Keywords: Econophysics. Sociophysics. Complex systems.

\section{ORIGENS}

A concepção atual de sociofísica teve sua origem nos modelos de Serge Galam e colaboradores nos anos 1980, com alguns precursores dos anos 1970 (SOCIOPHYSICS, 2004). ${ }^{1}$ No entanto, a sociofísica também é frequentemente descrita como "física social", termo que já havia sido definido pelo próprio Auguste Comte (COMTE, 1856), considerado um dos fundadores da sociologia.

[...] entendemos por física social a ciência que a por objeto próprio de estudo os fenômenos sociais, considerados no mesmo espírito que os fenômenos astronômicos, físicos, químicos e fisiológicos, isto é, sujeitos a leis naturais invariáveis, cuja descoberta é o objetivo especial de suas pesquisas. Assim, ela se propõe a explicar diretamente, com a maior precisão possível, o grande

\footnotetext{
${ }^{1}$ Desde o Acordo Ortográfico de 1990, a inicial maiúscula passou a ser opcional nos "domínios do saber, cursos e disciplinas" (<http://www.portaldalinguaportuguesa.org/main.html?action=acordo\&version=1990>). Por simplicidade, usamos iniciais minúsculas sempre que possível.
} 
fenômeno do desenvolvimento da espécie humana, apreciado em todas as suas partes essenciais $[\ldots]^{2}$

(COMTE, 1825, p. 355, tradução nossa)

Comte adotou o nome "sociologia" para sua nova ciência após descobrir que o estatístico belga Adolphe Quételet havia apropriado o termo "física social" para sua abordagem estatística da sociedade. A ideia de física social de Quételet pode estar mais próxima da sociofísica moderna que a ideia de Comte. Quételet considerava que os princípios da física poderiam ser transportados ao estudo do ser humano, pois esses dois mundos apresentariam leis análogas.

[...] a maioria das leis da mecânica encontram suas análogas quando se passa do mundo físico ao mundo moral.

Existe também uma correlação entre as ciências que tratam do homem dentro dessas duas ordens de coisas; isso quer dizer que duas ciências análogas caminham sempre de frente e apresentam os mesmos princípios que se traduzem quase da mesma maneira, aplicadas seja ao físico seja ao moral.

Além disso, não tenho ilusões sobre o valor desse trabalho. Considero-a como não mais que um esboço muito incompleto de uma ciência nova que tende a emergir, e que tem por objeto estudar o homem em seus diversos graus de agregação, deste o estado individual até o estado de combinação mais elevada que compreende toda a humanidade. ${ }^{3}$

\section{(QUÉTELET, 1848, p. XI, tradução nossa)}

O termo "econofísica" é bem mais recente e parece ter sido criada de forma menos formal que "sociofísica". Mandelbrot cita os econofísicos como herdeiros de sua descrição da economia por meio de fractais:

\footnotetext{
${ }^{2}[. .$.$] nous entendons par physique sociale la science qui a pour objet propre l'étude des phénomènes$ sociaux, considérés dans le même esprit que les phénomènes astronomiques, physiques, chimiques et physiologiques, c'est-à-dire comme assujettis à des lois naturelles invariables, dont la découverte est le but spécial de ses recherches. Ainsi, elle se propose directement d'expliquer, avec le plus de précision possible, le grand phénomène du développement de l'espèce humaine, envisage dans toutes ses parties essentielles [...]

${ }^{3}[\ldots .$.$] la plupart même des lois de la mécanique trouvent leurs analogues quand on passe du monde$ physique au monde moral.

Il existe aussi une corrélation entre les sciences qui concernent l'homme dans ces deux ordres de choses ; c'est-à-dire que deux sciences analogues marchent toujours de front et présentent les mêmes principes qui se traduisent à peu près de la mème manière, en les appliquant soit au physique soit au moral.

Je ne me fais du reste pas illusion sur la valeur de cet ouvrage. Je ne le considère que comme une esquisse fort incomplète d'une science nouvelle qui tend à se faire jour, et qui a pour objet d'étudier l'homme dans ses divers degrés d'agrégation, depuis l'état individuel, jusqu'à l'état de combinaison le plus élevé qui comprend l'humanité tout entière.
} 
Minhas percepções mais velhas e melhor corroboradas influenciam agora alguns dos modelos matemáticos por meio dos quais negociantes precificam opções e bancos avaliam riscos. Minha abordagem científica dos mercados tem sido imitada por uma nova geração daqueles que se chamam "econofísi$\cos ^{\prime \prime} .4$

(MANDELBROT; HUDSON, 2004, p. 7, tradução nossa)

Por outro lado, Mandelbrot frequentemente citava Louis Bachelier como um pioneiro na aplicação de teorias físicas ao estudo dos mercados, com sua tese Théorie de la Speculation, na qual aplica a ideia de movimento browniano ao estudo dos preços de ativos em bolsas de valores. Mandelbrot substituiu a descrição de Bachelier, que tinha base em movimento browniano e distribuições normais (gaussianas), por uma descrição fundada no conceito de fractais e distribuições de caudas longas.

\section{O QUE FAZEM ECONOFÍSICOS E SOCIOFÍSICOS?}

Não é muito comum que um pesquisador se defina como econofísico ou sociofísico. Muitos trabalhos científicos são classificados nos campos econofísica ou sociofísica sem que os seus autores utilizem esses termos explicitamente. Didier Sornette é considerado um pioneiro da econofísica e tem usado um mesmo modelo (das oscilações log-periódicas) para prever rupturas mecânicas, terremotos, ataques epilépticos e quebras nas bolsas de valores. No entanto, seu clássico Why Stock Markets Crash traz a palavra econophysics apenas duas vezes, e apenas nas referências bibliográficas! Por outro lado, o termo physics aparece 104 vezes, nada mal para um livro sobre mercados de ações. Talvez os pesquisadores evitem os termos para evitar a possível oposição que possa haver à definição desses campos de estudo. Para termos uma amostra de trabalhos que sejam inequivocamente classificados nesses campos, recorremos a um livro que apresenta uma coletânea de trabalhos sob o título "Econofísica e Sociofísica" (CHAKRABARTI; CHAKRABORTI; CHATTERJEE, 2006). Cada capítulo desse livro é escrito por um pesquisador diferente no formato de artigo científico. Assumimos que esses pesquisadores assumam-se como econofísicos ou sociofísicos, implícita ou explicitamente, pelo próprio fato de contribuírem com capítulos num livro de título Econophysics and Sociophysics.

Num dos capítulos dos livro, Juergen Mimkes apresenta uma "formulação termodinâmica da economia", na qual reinterpreta as grandezas das leis da termodinâmica, de modo a obter "leis da economia". Calor passa a ser superávit, energia interna vira capital e trabalho é interpretado como produção. Num outro capítulo, o mesmo autor apresenta uma "formulação termodinâmica da ciência social", na qual associa energia a emoções e temperatura à tolerância à desordem. Também compara sociedades coletivistas à estrutura bem organizada dos sólidos e sociedades individualistas ao estado líquido, com menor organização em nível atômico.

\footnotetext{
${ }^{4} \mathrm{My}$ oldest, best-corroborated insights now influence some of the mathematical models by which traders price options and banks evaluate risk. My scientific approach to markets has been emulated by a new generation of those who call themselves "econophysicists."
} 
O modelo de Ising é usado em algumas das aplicações apresentadas no livro. Inicialmente utilizado para explicar o ferromagnetismo, esse modelo é hoje usado para simular sistemas dos mais diversos tipos. No modelo, há uma cadeia de spins atômicos igualmente espaçados e a orientação de spin é influenciada pelos spins vizinhos e por um campo magnético aplicado sobre todo o sistema. Há também efeitos da temperatura que tendem a desalinhar os spins, alterando suas orientações aleatoriamente. De modo geral, o modelo de Ising representa uma competição entre três efeitos: alinhamento mútuo entre os agentes, alinhamento com um agente central e desalinhamento devido a fenômenos desconhecidos (agitação térmica). Descrito dessa forma, é difícil saber se o modelo de Ising descreve fenômenos magnéticos ou se descreve interação entre pessoas. Não por acaso, o modelo é amplamente utilizado para simular dinâmicas sociais e economia.

A seguir, apresentamos os títulos e autores de alguns capítulos do livro (CHAKRABARTI; CHAKRABORTI; CHATTERJEE, 2006), destacando a analogia entre os objetos físicos e os objetos econômicos ou sociais, assim como alguns métodos e resultados apresentados:

\section{A Thermodynamic Formulation of Economics}

Juergen Mimkes

Objetos físicos: energia, entropia, trabalho etc.

Objetos econômicos ou sociais: capital, excedente, produção etc.

Métodos: leis da termodinâmica reescritas como leis da economia.

Resultados: fundação teórica da função de produção de Cobb-Douglas, dedução de leis econômicas, explicação de dados reais de PIB e produção etc.

\section{Zero-intelligence Models of Limit-order Markets}

Robin Stinchcombe

Objetos físicos: sistema de partículas que interagem entre si e com uma supefície por meio de processos de deposição, posicionamento, aniquilação, remoção etc.

Objetos econômicos ou sociais: ordens de compra e venda, com formação de preços e transações em bolsas de valores.

Métodos: simulação Monte Carlo.

Resultados: leis de potência de retornos de ações, clusterização da volatilidade, simulação do mercado em diferentes regimes, cálculo dos expoentes de Hurst dos sistemas etc.

\section{Understanding and Managing the Future Evolution of a Competitive Multi-agent Population}

David M.D. Smith, Neil F. Johnson

Objetos físicos: sistemas complexos adaptativos de forma geral, sem citação explícita de um exemplo físico.

Objetos econômicos ou sociais: população de $N$ agentes que repetidamente tomam ações em alguma forma de um jogo global; como 
exemplo, o mercado financeiro.

Métodos: simulação Monte Carlo, processos de Markov, teoria de jogos.

Resultados: método de previsão de tendências do sistema (futurecasting) por meio de uma matriz do operador Future-Cast.

\section{Growth of Firms and Networks}

Yoshi Fujiwara, Hideaki Aoyama, Wataru Souma

Objetos físicos: lei de Zipf-Pareto, condição de balanço detalhado; o artigo não cita um exemplo físico, mas a lei de Zipf-Pareto descreve várias distribuições de frequência estatística: massas de corpos celestiais, intensidade de terromotos, ocorrência de palavras em idiomas, receita de empresas, populações de cidades etc.; a condição de balanço detalhado foi inicialmente introduzida por Boltzmann em mecânica estatística e termodinâmica.

Objetos econômicos ou sociais: receita e crescimento de empresas. Métodos: lei de Zipf-Pareto, lei de Gibrat (sobre o crescimento de empresas).

Resultados: definição dos regimes de mercado nos quais valem a lei de Zipf-Pareto, a lei de Gibrat e a condição de balanço detalhado, o que pode ajudar a entender falências de empresas em cadeia.

\section{A Review of Empirical Studies and Models of Income Distributions in Society}

Peter Richmond, Stefan Hutzler, Ricardo Coelho, Przemek Repetowicz

Objetos físicos: sistemas de partículas.

Objetos econômicos ou sociais: distribuição de renda intra-população e entre duas populações (de países).

Métodos: lei de Pareto, leis de potência, função de Boltzmann, modelos baseados em agentes: modelo da rede familiar, modelo de Lotka Volterra generalizado etc.

Resultados: reprodução de aspectos de distribuições de renda reais por meio de simulações computacionais; em especial, reproduziram o fato observado de que a distribuição de renda segue a lei de Pareto na faixa de alta renda, mas se desvia dela na faixa de baixa renda.

\section{A Thermodynamic Formulation of Social Science}

Juergen Mimkes

Objetos físicos: sistemas atômicos, princípio de Lagrange, energia, temperatura, energia livre, entropia etc.

Objetos econômicos ou sociais: sociedade, princípio da máxima felicidade, leis coletivas, comportamento individual, tolerância, felicidade etc.

Métodos: leis da termodinâmica reescritas como leis sociais. 
Resultados: descrição teórica de diversos conceitos e fenômenos sociais, tais como coletivismo, individualismo, democracia, hierarquia, segregação etc.

\section{Computer Simulation of Language Competition by Physicists Christian Schulze, Dietrich Stauffer}

Objetos físicos: não há referência a um sistema físico central, mas uma comparação com fenômenos críticos em física estatística; os métodos utilizados são mais frequentes em modelos biológicos, mas também aparecem em fenômenos de auto-organização e formação de estruturas (p.ex. cristais).

Objetos econômicos ou sociais: línguas (idiomas) em dispersão, diferenciação e interação.

Métodos: simulações da difusão de línguas em um território inicialmente vazio, com diferenciação e interação mútua, por meio de diversos recursos: equação (diferencial) de Verhulst e sua solução (função logística), autômatos celulares, simulação Monte Carlo etc.

Resultados: reprodução de dados estatísticos dos idiomas, como a distribuição das famílias linguísticas em função do número de línguas que contêm, mapas linguísticos etc.

\section{Social Opinion Dynamics}

Gérard Weisbuch

Objetos físicos: momentos magnéticos (spins), ferromagnetismo, modelo de Ising etc.

Objetos econômicos ou sociais: opiniões, persuasão, cultura etc.

Métodos: autômatos celulares, dinâmica probabilística etc.

Resultados: simulação do agrupamento das opiniões em polos (polarização), análise do efeito da presença de agentes mais informados (menos influenciáveis) na população etc.

\section{Global Terrorism versus Social Permeability to Underground Activities Serge Galam}

Objetos físicos: materiais que apresentam o fenômeno da percolação, que é a formação de uma rede contínua de partículas por agregação, como na transição sol-gel.

Objetos econômicos ou sociais: terroristas e seus "apoiadores passivos" (não terroristas que simpatizam com a causa ou não se opõem). Métodos: teoria da percolação.

Resultados: cálculo da porcentagem de apoiadores passivos na população que causa a transição de focos de terrorismo local para o fenômeno do terrorismo global. 
O livro apresenta vinte trabalhos de econofísica e sociofísica que valem a pena ser lidos, mas os exemplos apresentados acima são suficientes para ilustrar esses campos ao leitor para os propósitos desta análise.

\section{OPOSIÇÕES FREQUENTES}

\section{III.1. Por que a Física?}

No livro "O grande, o pequeno e a mente humana" (PENROSE et al., 1998), o físico Roger Penrose propôs uma tese ousada sobre a existência de efeitos quânticos nos neurônios e convidou Abner Shimony, Nancy Cartwright e Stephen Hawking para escreverem críticas ao texto principal, críticas que foram respondidas e anexadas ao fim do livro. Em sua crítica, o físico Stephen Hawking começa por se reconhecer como um "reducionista desavergonhado" que acredita que as leis da biologia podem ser reduzidas às leis da química e que as leis da química podem ser reduzidas às leis da física.

Para começar, devo dizer que sou um reducionista desavergonhado. Acredito que as leis da biologia podem ser reduzidas às leis da química. Já vimos isso acontecer com a descoberta da estrutura do DNA. E eu acredito ainda que as leis da química podem ser reduzidas às leis da física. Acho que a maioria dos químicos concordaria com isso. ${ }^{5}$

(PENROSE et al., 1998, p. 169, tradução nossa)

Nesse aspecto, Hawking concorda com Penrose, mas discorda ao se considerar um "positivista que acredita que as teorias físicas são apenas modelos matemáticos que construímos", enquanto considera Penrose como "um platonista que acredita que há um único mundo de ideias que descreve uma única realidade física" (PENROSE et al., 1998, p. 169). Por outro lado, a bióloga Nancy Cartwright inicia sua crítica com o título "Por que a Física?", 6 e ataca a ideia de que o mundo é um sistema unificado, tendo a física como a base da unificação, e afirma que leis biológicas não são reduzidas às leis da física porque não precisam ser definidas em termos físicos (PENROSE et al., 1998, p. 163-164). Em sua resposta, Penrose afirma não saber claramente que tipo de linha possa ser traçada entre física e biologia.

Essa orientação filosófica sustenta que as ciências "reduzem-se" umas às outras. Werner Heisenberg, no livro "Física e Filosofia" (HEISENBERG, 1959/1995), argumentou que a mecânica quântica unificou física e química nas mesmas leis básicas. Também previa que a biologia, a psicologia e as ciências sociais também acabariam sendo unificadas com a física e química numa só ontologia. De fato, a divisão da ciência em campos como física, química e sociologia não é uma imposição pelo Universo, mas uma conveniência humana. O que separa as ciências são os objetos de interesse, os pontos de vista, as metodologias etc. A

\footnotetext{
${ }^{5}$ To start with, I should say I'm an unashamed reductionist. I believe that the laws of biology can be reduced to those of chemistry. We have already seen this happening with the discovery of the structure of DNA. And I further believe that the laws of chemistry can be reduced to those of physics. I think most chemists would agree with that.

${ }^{6}$ WHY PHYSICS?
} 
demonstração de que as mesmas leis básicas sirvam de fundamentando ontológico para duas ciências não implica a inutilidade de nenhuma delas. Embora, em teoria, a maioria dos fenômenos químicos poderia ser deduzidos diretamente da equação de Schrödinger, isso exigiria uma quantidade de cálculo impossível de ser realizada mesmo pelos computadores mais potentes, de modo que os químicos ainda usam leis empíricas e aproximações em diferentes níveis.

No prefácio do livro Econophysics and Sociophysics (CHAKRABARTI; CHAKRABORTI; CHATTERJEE, 2006), os organizadores citam a história budista dos "cegos e o elefante", na qual cada cego toca uma parte diferente do elefante para tentar descobrir como um elefante é. Um toca a cauda e diz que um elefante se parece com uma cobra, outro toca a perna e diz que o elefante se parece com uma árvore, e assim por diante. Com essa história, sugerem que físicos, biólogos, economistas e sociólogos enxergam o mesmo universo de pontos de vista diferentes:

A natureza dificilmente se importa se nosso ponto de vista é físico, biológico ou sociológico. Os estudos de complexidade visam capturar esses códigos universais, manifestados diferentemente em diferentes partes do mesmo corpo de fenômenos naturais. Hoje, essa pesquisa de grande unificação está em uma fase muito inspiradora e este livro relata uma parte desses estudos interdisciplinares, desenvolvidos nos últimos dez a quinze anos e classificados principalmente sob os títulos econofísica ou sociofísica. ${ }^{7}$

(CHAKRABARTI; CHAKRABORTI; CHATTERJEE, 2006, p. XXII, tradução noss

Nossa experiência diz que esse reducionismo ontológico está longe de como pensam os cientistas sociais deste tempo, mas é notável no pensamento de pioneiros das ciências sociais, como o próprio Comte:

Para conhecer com toda a precisão necessária a verdadeira época em que esta grande revolução chegou, é necessário distinguir, na última ciência (fisiologia), a seção relativa às funções intelectuais e afetivas, da que inclui as demais funções orgânicas.

Foi somente depois de todos os outros que os fenômenos morais deixaram o domínio da teologia e da metafísica para entrar no domínio da física.

$[\ldots]$

Assim, agora temos uma física celeste, uma física terrestre, mecânica ou química, uma física vegetal e uma física animal: falta-nos ainda uma última,

\footnotetext{
${ }^{7}$ Nature hardly cares whether our views are physical, biological, or sociological. The complexity studies aim to capture these universal codes, manifested differently in differ ent parts of the same body of natural phenomena. This grand unification search is at a very inspiring stage today and this book reports on a part of these interdisciplinary studies, developed over the last ten to fifteen years and classified mainly under the headings econophysics or sociophysics.
} 
a física social, para que o sistema de nosso conhecimento natural esteja completo. ${ }^{8}$

(COMTE, 1972, p. 352)

A física social de Comte está inserida na ideia maior de "filosofia positiva" (positivismo), frequentemente considerada como "superada" pelos cientistas sociais, juntamente com muitas outras ideias historicamente relacionadas a ela.

Em 2019, Marina O. Silva, então estudante de Ciências Sociais da Universidade de Brasília, observou lições de uma turma de Tópicos Especiais com o tema "Econofísica e Sociofísica", no Instituto de Física, como uma atividade de pesquisa requerida numa disciplina do curso de Ciências Sociais. O trabalho estimulou o diálogo entre estudantes de física e de ciências sociais e foi publicado na revista Physicae Organum (SILVA, 2019). O artigo descreve o afastamento que as ciências sociais tiveram dos paradigmas originais da sociologia como física social:

Por um processo de especialização, problematização e reformulação dos pressupostos teóricos e metodológicos das ciências sociais, percebe-se um afastamento das concepções que tentam encarar os fenômenos sociais e a sociedade por meio de paradigmas do positivismo científico, darwinismo social e evolucionismo cultural. Sendo assim, os campos das ciências sociais e naturais se afastam drasticamente, sendo muito difícil o estabelecimento de qualquer tipo de interlocução, uma vez que em alguns casos estes paradigmas serviram para legitimar teorias racistas, eugênicas e etnocêntricas.

(SILVA, 2019, p. 2)

Em sua conclusão, Silva reconhece as diferentes "realidades performadas" por cientistas sociais e sociofísicos, mas expressa a rejeição existente nas ciências sociais ao tipo de abordagem utilizado na sociofísica:

O que fica muito evidente, ao meu ver, é que os/as cientistas sociais, diante de um passado histórico controverso, rejeitam performatividades de fenômenos sociais que levem em consideração uma visão de que os fenômenos

\footnotetext{
Afin de connaître avec toute la précision nécessaire la véritable époque à laquelle est maintenant parvenue cette grande révolution, il faut distinguer, dans la dernière science (la physiologie), la section relative aux fonctions intellectuelles et affectives, d'avec celle qui comprend les autres fonctions organiques.

Ce n'est qu'après tous les autres que les phénomènes moraux sont sortis du domaine de la théologie et de la métaphysique, pour entrer dans celui de la physique.

$[\ldots]$

Ainsi, nous possédons maintenant une physique céleste, une physique terrestre, soit mécanique, soit chimique, une physique végétale, et une physique animale : il nous en faut encore une dernière, la physique sociale, afin que le système de nos connaissances naturelles soit complet.
} 
poderiam ser captados e ordenados por meio de análises físicas, matemáticas ou biológicas, uma vez que compreendem que as relações sociais são muito complexas para serem encaixadas nesses sistemas. Além do perigo que essas abordagens podem apresentar, no sentido de poderem ser universalizantes, elas ainda podem servir para legitimar discursos problemáticos.

(SILVA, 2019, p. 3)

Por outro lado, pela nossa experiência, a oposição de economistas à econofísica costuma ser bem diferente da oposição dos cientistas sociais à sociofísica. Enquanto cientistas sociais tendem a rejeitar modelos matemáticos, economistas estão habituados a eles. Já ouvimos a alegação de que criar modelos econômicos é o trabalho dos próprios economistas, não havendo assim a necessidade de se falar em econofísica, mas a opinião de economistas e analistas financeiros parece bem variada, desde o reconhecimento de que a física contribuiu com a economia desde os seus primórdios (HAMADA, 2002) até a ideia de que a economia é uma ciência social e não pode ser tratada como física e química (FERNANDO, 2010). Para complicar, não há nem mesmo um consenso sobre a diferença fundamental entre econofísica e economia financeira. Ausloos et al. (AUSLOOS; JOVANOVIC; SCHINCKUS, 2018) afirmam que a ideia mais difundida sobre a diferença entre econofísicos e economistas financeiros é que os econofísicos estudam os problemas por uma abordagem bottom-up (mais "microscópica") enquanto os economistas financeiros os estudam por uma abordagem top-down (partindo de expectativas racionais e da hipótese do mercado eficiente). Os autores consideram essa divisão confusa, não permitindo revelando a essência da diferença entre os campos de estudo, e afirmam uma diferença de caráter mais técnico: ambos sabem que a distribuição de probabilidade de retornos de ações não são bem descritas por uma gaussiana (como se pensava no passado), mas tratam os valores extremos que desviam dessa distribuição de formas diferentes.

A diferença refere-se à maneira de modelar os valores extremos: os econofísicos consideram esses valores como parte do sistema, enquanto os economistas associam esses valores extremos a termos de erro aos quais eles fornecem uma distribuição estatística. ${ }^{9}$

(AUSLOOS; JOVANOVIC; SCHINCKUS, 2018, p. 5, tradução nossa)

Em nossa avaliação, o que marca a maioria dos trabalhos classificados como econofísica e sociofísica é a aplicação de métodos tradicionalmente usados nas ciências físicas à economia. ${ }^{10}$ Essa ideia, contudo, leva a outra questão: uma vez que o objeto físico é substituído pelo objeto econômico, o que restou de física? Quando os objetos físicos são subtraídos dos métodos da física, não seria apenas matemática o que sobra? De fato, existem campos do

\footnotetext{
${ }^{9}$ The difference refers to the way of modelling the extreme values: econophysicists consider these values as a part of the system while economists rather associate these extreme values with an error terms to which they give a statistical distribution.

${ }^{10}$ Ciências físicas inclui física, astronomia, química e geologia. A maior parte do que falamos sobre física pode ser generalizado para ciências físicas.
} 
conhecimento como matemática financeira, economia matemática, sociometria e sociologia matemática, que também usam recursos matemáticos e estatísticos sem a necessidade de ter "física" no nome, embora alguns pioneiros dessas áreas, como Bachelier na matemática financeira e Quételet na sociologia matemática, também utilizavam ideias vindas da física.

Somos tentados a pensar que a novidade levada pelos físicos seja o uso da matemática, mas a matemática não é totalmente ignorada nas ciências humanas como alguns podem pensar. Técnicas estatísticas são estudadas nas ciências sociais e na psicologia sob a designação de "métodos quantitativos" (GORARD, 2003). A criminologia é em grande parte fundamentada em dados estatísticos e metodologia científica, de modo que conclusões vindas de estudos que não cumpram certas exigências mínimas de rigor metodológico podem ser simplesmente ignoradas (SHERMAN et al., 2002). O uso da matemática na sociologia cresceu muito desde os anos 1960 (EDLING, 2002). A representação de redes sociais como grafos é algo corriqueiro para alguns cientistas sociais, que também usam conceitos estatísticos frequentemente: testes de hipótese, probabilidade de significância (valor-p), testes não paramétricos etc. Muitos desses métodos estatísticos, também amplamente utilizados nas ciências médicas e biológicas, são frequentemente ignoradas pelos próprios físicos. Isso acontece porque a variação entre elementos (indivíduos) de uma amostra é muito mais relevante para cientistas que estudam seres vivos (incluindo humanos) que para os físicos e químicos, cujos experimentos ou envolvem isolamento de poucos elementos e fino controle do ambiente ou, pelo contrário, envolvem tanta variação que é mais fácil trabalhar com grandezas macroscópicas como temperatura e pressão.

Curiosamente, a maior parte dos métodos da econofísica e da sociofísica vêm da subárea da física na qual os métodos estatísticos fazem-se mais presentes, a mecânica estatística. A diferença é que os métodos estatísticos não são aplicados a amostras reais, mas sim para se relacionar grandezas macroscópicas (pressão, temperatura, calor específico etc.) a características dos átomos constituintes não observadas individualmente (velocidade, posição, momento angular etc.). Substitua essas propriedades atômicas por comportamentos humanos e obtenha a econofísica e a sociofísica. Esse tipo de uso da estatística no estudo da economia e da sociedade é diferente do que é mais comum. Ao invés de analisar dados reais estatisticamente para se formular hipóteses, faz-se o caminho contrário: formula-se as hipóteses e dados fictícios são gerados. Se os dados fictícios forem similares a dados reais, as hipóteses provavelmente são boas. Assim, uma competição profissional com sociofísicos dificilmente seria um problema para cientistas sociais. Físicos, quando se embrenham nesses assuntos, tendem a se concentrar em reconhecer padrões gerados em simulações, mas dependem de hipóteses para criar os modelos e de dados reais para testar as conclusões. Essas hipóteses e dados seguramente virão de estudos das ciências sociais.

Para decidirmos se a parte "física" de sociofísica e econofísica são justificados, obviamente temos que termos bem clara nossa definição de física. O que define a física são os objetos ou os métodos? Que objetos e métodos são esses? Alguns definem física como o estudo da natureza, da realidade concreta, da matéria e da energia, ou mesmo de tudo o que pode se objeto de experiência.

Física/físico: o termo "físico" designa a realidade material, concreta, objeto de nossos sentidos, em contraste com a realidade psíquica, subjetiva, interior, 
bem como a realidade espiritual ou abstrata.

(JAPIASSÚ; MARCONDES, 2008, p. 113)

Físico: o adjetivo designa de modo geral o que concerne à natureza. Mais especialmente, designa, por oposição à metafísica, o que pertence ao mundo fenomenal e pode ser objeto de experiência.

(DUROZOI; ROUSSEL, 1993, p. 192)

Considerando esse tipo de definição, pode-se entender que sociofísica e econofísica adotam uma postura materialista, transferindo o comportamento humano da realidade psíquica, subjetiva e metafísica à realidade material, concreta e fenomenal. Todavia, uma tal crítica poderia ser estendida à maioria das ciências humanas, cujas metodologias também incluem descrição da realiade concreta e fenomenal.

Por outro lado, o filósofo Nicola Abbagnano reconhece o mais recente conceito de física como "previsão do observável":

Podemos distinguir três conceitos fundamentais dessa ciência, que se sucedem ao longo da história: $1^{\circ} \mathrm{F}$. como teoria do movimento; $2^{\circ} \mathrm{F}$. como teoria da ordem necessária; $3^{\circ} \mathrm{F}$. como previsão do observável.

(ABBAGNANO, 2000, p. 439)

Comte justificava o uso do termo "física social" com a ideia de que seus pesquisadores buscariam "leis naturais e invariáveis". Por outro lado, a ideia de sociofísica de Serge Galam relaciona-se à transposição de métodos de modelagem da física às ciências sociais. Temos, assim, dois tipos de justificativa para a inclusão de sociofísica e econofísica como áreas da física.

\section{III.2. O ser humano é muito complexo}

Uma crítica comum à econofísica e à sociofísica é que o ser humano não pode ser tratado de forma tão simples quanto corpos rígidos, átomos, moléculas etc. Algumas vezes, há mesmo um certo romantismo na maneira que essa objeção é feita. Como pode o espírito humano ser descrito por algumas equações? Recusamos a aceitar que somos seres previsíveis. O que muitos não sabem é que modelos físicos também envolvem significativa simplificação da realidade sem deixar de ter utilidade e poder preditivo. Físicos estão acostumados a lidar com os limites de seus próprios modelos. Mesmo os estudantes do ensino médio já se acostumam a simplificações como resistência do ar desprezível, superfície sem atrito, gases ideais etc. Em eletrodinâmica quântica, mesmo uma partícula elementar como o elétron parece ser uma estrutura complexa se analisada em outras escalas de energia e distância. 
Aparentemente, toda a física é uma profunda simplificação de uma complexidade infinita que poderia ser observada se os sistemas fossem vistos de mais perto.

Uma piada comum entre os cientistas conta que a primeira coisa que um físico fez ao tratar um certo problema agropecuário foi aproximar as vacas como esferas, para fins de cálculos. A expressão "vaca esférica" é comumente usada como uma referência às simplificações feitas pelos físicos quando criam seus modelos. Essa expressão foi utilizada como referência a modelos simples de modelagem ambiental no livro "Considere uma vaca esférica" (HARTE, 1991), seguido de outro livro com modelos um pouco mais elaborados: "Considere uma vaca cilíndrica" (HARTE, 2001). O sucesso da metáfora da vaca esférica nas ciências naturais mostra que eles têm consciência de que seus modelos e teorias têm limites de validade, mas mesmo assim esses modelos e teorias têm sido aplicados com sucesso para inúmeros propósitos.

Se o ser humano é complexo demais para ser descrito por meio de equações matemáticas, por que seria possível descrevê-lo por meio de qualquer texto? Em que medida uma equação matemática tem menor poder descritivo que uma sentença em português? Uma fórmula matemática somente tem sentido de seus símbolos forem previamente definidos com precisão. Nas ciências físicas, as grandezas utilizadas são normalmente definidas pelos procedimentos pelos quais podem ser medidas. Por que isso não pode ser feito também nas ciências humanas, nas quais estudos estatísticas e experimentos psicológicos são frequentemente realizados? A restrição a propriedades que possam ser medidas certamente limita o escopo de um tal estudo, mas isso não é necessariamente ruim, pois ajuda a estabelecer os limites de validade da teoria resultante.

Em contraste com símbolos de fórmulas matemáticas, qualquer palavra de um idioma múltiplas definições no dicionário e um campo semântico que pode dar margem a diversas interpretações. É claro que palavras também podem ser definidas com precisão, tornando-se termos técnicos em certos campos do conhecimento, mas essa não é uma prática que se faz sempre presente em textos das ciências humanas. Frequentemente, considera-se que o significado de um termo é bem conhecido numa certa área e dispensa-se sua definição. Por exempo, Annemarie Mol afirma que o termo "ontologia" nas ciências sociais tem diferentes significados quando usados por diferentes autores e que seu grupo começou a brincar com esse termo de maneira provocativa e deram a ele um novo significado. Naturalmente, será possível entender o novo sentido através de inúmeras leituras que o exemplificam pelo próprio uso. Isso também é feito na matemática e nas ciências físicas, através de textos, exercícios e problemas. A diferença é que a matemática oferece um maior poder de concisão depois que seus símbolos estão bem compreendidos. As quatro equações de Maxwell, por exemplo, podem ser sintetizadas em uma só equação, usando álgebra de Clifford, ou expandidas na forma de doze equações, se decomposta em coordenadas cartesianas. Esse poder de sintetização torna possível o estudo de um problema em diferentes níveis de detalhamento, conforme o interesse do pesquisador. Além disso, quem lê artigos de matemática sabe que eles não são totalmente escritos com uma sequência ininterrupta de símbolos lógicos e matemáticos. Os textos têm frases, assim como os textos das ciências humanas, e alguns teoremas podem ser enunciados sem nenhuma referência a variáveis e equações.

Fórmulas matemáticas representam ferramentas a mais, não a menos, e por isso não 
necessariamente serão fatores limitantes na abordagem sociofísica. O que de fato poderia limitar a atuação de um físico nesses campos seria a crença de que um profundo conhecimento matemático poderia compensar o desconhecimento sobre fenômenos sociais e econômicos. O econofísico e o sociofísico também tem a obrigação de estudar esses temas a fundo, se possível em colaboração com outros profissionais. Uma vez garantido que o sociofísico conheça bem o seu objeto de estudo e as metodologias que lhe são próprias, ferramentas matemáticas poderão ser muito úteis para ter hipóteses e conclusões melhor definidas e transmiti-los em forma mais sintética. Tomemos como exemplo o debate sobre o desarmamento. Um lado diz que mais armas de fogo causa mais mortes, enquanto o outro lado alega que a posse de armas inibe a ação de criminosos por representar uma possibilidade de defesa do cidadão. Se não recorrermos a estudos estatísticos, cada uma dessas afirmações só pode ser contestada ao se afirmar que um fenômeno é mais efetivo que o outro. Por outro lado, quando um problema é abordado pela técnica da "dinâmica de sistemas", as várias possíveis relações de causalidade são listadas e a proporcionalidade entre todas as quantidades envolvidas é representada por um fator. Isso permite que várias simulações sejam feitas, considerando várias combinações de valores para esses fatores e avaliando os possíveis cenários futuros. As simulações também geram gráficos da evolução temporal das quantidades envolvidas, que podem ser comparadas com dados reais para descobrir que conjuto de fatores representa os dados com maior fidelidade. Contudo, a maior vantagem dos esquemas de dinâmica de sistemas talvez seja o provimento de um modelo mental sofisticado para se pensar sobre os problemas. Se as questões sociais são mais complexas, tanto mais desejável que os modelos mentais sejam mais sofisticados.

\section{III.3. A realidade é subjetiva e alterada pelo próprio pesquisador}

Uma outra oposição a regras do tipo matemático para descrever a sociedade é a ideia de que a realidade é subjetiva e o próprio cientista altera a realidade que estuda. Estudos antropológicos são, com razão, descritos como uma interação entre dois sujeitos, cada um com sua própria cultura. A efeito do observador no sistema tampouco é desconhecido na Física e é de fato um tema central no debate entre as interpretações da Física Quântica. Descobertas como o teorema da incompletude de Gödel e a teoria do caos fizeram com que os físicos adotassem descrições alternativas ao determinismo. Por outro lado, a questão da universalidade está longe de ser pacífica nas Ciências Sociais.

Silva (SILVA, 2019) aborda a interdisciplinaridade entre ciências sociais e sociofísica com referência ao conceito de "políticas ontológicas", chegando à conclusão de que os fenômenos sociais são performados como objetos diferentes nas ciências sociais e na sociofísica:

No caso específico que irei estudar, os objetos aparecem enquanto fenômenos sociais. Sendo assim, as ciências sociais irão performar essas objetos de uma forma, enquanto a sociofísica irá performar de outra diferente. Esses objetos não são iguais, mas coexistem, e a partir do momento que eles se chocam, alguns problemas começam a surgir.

(SILVA, 2019, p. 3) 
A ideia de "políticas ontológicas" foi desenvolvida por Annemarie Mol ${ }^{11}$ ao estudar como doenças médicas são definidas de formas distintas num hospital por profissionais de saúde de especialidades diferentes. Para ela, essas diferenças mostram que os objetos existem como articulações das práticas que os produzem. Mol descreve a existência de diferentes "realidades performadas" pelas práticas, mas também fala em "versões da realidade conectadas entre si" (MARTIN; SPINK; PEREIRA, ). Essa conexão entre as versões da realidade deve ocorrer em algum campo, e esse campo é o que os físicos chamariam de "a realidade" propriamente dita. Assim, embora a ideia de "políticas ontológicas" pareça afastada do realismo típico dos físicos, é notável a semelhança com ideias da teoria da relatividade, por exemplo, ou com o teorema de Noether. A teoria da relatividade mostra que medidas de espaço e tempo variam de um referencial de observação a outro, porém de forma a manter algumas grandezas constantes de modo as observações ainda façam parte do mesmo universo e portanto estejam relacionadas. O teorema de Noether explica que cada lei de conservação da física (energia, momento, carga, massa etc.) pode ser deduzida de um tipo de simetria observada nas leis da natureza. Por exemplo, a conservação do momento linear corresponde ao fato de que as leis da física não mudam de um lugar a outro no universo.

O antropólogo Cristoph Antweiler atribui a relutância dos antropólogos culturais em aceitar a existência de características universais em culturas ao fato de que a diversidade é a moeda desses antropólogos:

Antropólogos culturais são, de forma geral, extremamente relutantes em reconhecer características universais em culturas, e com boa razão. A maioria dos antropólogos são antropólogos culturais, e antropologia cultural é sobre diversidade. De nenhuma maneira eu repudio a realidade da diversidade humana. Entretanto, eu apoio o reexame da teoria antropológica em favor de um olhar às similaridades panculturais. [...] Embora diferenças não sejam todo o foco das ciências culturais, elas são atualmente a principal 'moeda' global no pensamento sobre cultura. ${ }^{12}$

(ANTWEILER, 2016, p. XI, 4)

No entanto, o estudo dos "universais humanos" tem voltado a atrair a atenção de antropólogos contemporâneos (BROWN, 1991; ANTWEILER, 2016) que apresentam listas de padrões de cultura, sociedade, idioma e comportamento para os quais não existem exceções conhecidas. Eles também defendem que os próprios antropólogos que não aceitam a existência de universais frequentemente utilizam conceitos ou expressões que demonstram generalizações, de modo que sua opinião invalidaria seu próprio trabalho se fosse aplicada

\footnotetext{
${ }^{11}$ Em entrevista recente, Annemarie Mol afirmou preferir a tradução "ontologias políticas" (MARTIN; SPINK; PEREIRA, ).

${ }^{12}$ Cultural anthropologists are, in general, extremely reluctant to acknowledge universal features in cultures, and with good reason. Most anthropologists are cultural anthropologists, and cultural anthropology is about diversity. In no way do I dismiss the reality of human diversity. However, I support re-examining anthropological theory in favor of looking at pancultural similarities. [...] Although differences are not the entire focus of the cultural sciences, they are at present the leading global 'currency' in the thinking on culture.
} 
com rigidez. A existência de universais foi reconhecida ou defendida por inúmeras figuras ainda muito influentes nas ciências humanas, tais como Franz Boas, Noam Chomsky, JeanBaptiste Duroselle, Maurice Godelier etc., e a própria teoria marxista tem características fortemente universalistas (TALACHIAN, 2016). Deste modo, sociofísicos podem considerar que a questão da universalidade seja um "problema interno" das ciências humanas e continuar seus estudos até que o consenso seja estabelecido, ainda mais considerando a existência de padrões que são inegavelmente observados em dados vindas das ciências humanas, tais como a lei de Zipf-Pareto e a tendência à distribuição gaussiana (explicada pelo teorema do limite central). Ademais, modelos sociofísicos dificilmente partem da hipótese de que o comportamento humano possa ser previsto individualmente. A mecânica estatística é popular na sociofísica justamente porque seus modelos normalmente têm uma parte determinística e outra parte aleatória (estocástica). A parte estocástica representa as variações individuais de comportamento que não podem ser previstas, mesmo que existam hipóteses sobre sua distribuição de probabilidade. Embora o comportamento de um indivíduo não possa ser previsto, certas tendências de comportamento mediante certos estímulos podem ser apreciadas estatisticamente, como têm consistentemente mostrado vários estudos de psicologia experimental (FREEDMAN; FRASER, 1996; BEAMAN et al., ; KAHNEMAN, 2002; CIALDINI, 2009).

Na abordagem de Sornette (SORNETTE, 2017), as oscilações log-periódicas observadas em preços de ativos durante uma bolha financeira, e que poderiam ajudar a prever quebras no mercado, aparecem não porque os investidores não têm consciência da existência da bolha financeira, mas porque eles percebem que os preços estão sobrevalorizados e têm a expectativa do crash, mas preferem continuar arriscando na esperança de obter lucro enquanto os preços continuam subindo. A quebra ocorre quando a maioria dos investidores desistem de especular, percebendo que não há possibilidade de mais sobrevalorização dos ativos. O estatístico Nate Silver tem uma resposta semelhante à crítica de que a intervenção humana invalida as abordagens estatísticas nos fenômenos sociais:

Uma das críticas óbvias à hipótese de potência de Clauset é que, ao contrário de eventos como terremotos, a intervenção humana pode deter o terrorismo.

As pesquisas de Clauset sugerem que a distribuição da lei de potência existe não apesar da competição entre forças terroristas e contraterroristas, mas talvez por causa dela.

(SILVER, 2012, p. 449)

Silver mostra ainda que dados de terrorismo de Israel apresentam maior desvio da lei de potência que descreve esses dados para outros países e explica esse desvio pelo fato de que Israel tem uma estratégia de combate ao terrorismo incomum em relação aos outros países, mais focada à prevenção de atentados de grande escala. Isso indica que as leis estatísticas ajudam a compreensão da sociedade mesmo quando os dados reais fogem dessas leis. Relações causais podem ser até mais evidentes quando ocorrem desvios em relação a padrões conhecidos. 


\section{Sistemas dinâmicos, Sistemas complexos, CiÊnCia de Dados...}

A teoria dos sistemas dinâmicos, que remonta aos trabalhos do matemático Henri Poincaré (MONTEIRO, 2011; APLICADA, 2020), também tem sido aplicada ao estudo de fenômenos econômicos e sociais, assim como à astronomia, biologia, engenharia, física, geologia, matemática, medicina, meteorologia e química (MONTEIRO, 2011). A chamada "teoria da complexidade" (MITCHELL, 2009) apresenta considerável afinidade e sobreposição de temas com a teoria dos sistemas dinâmicos, o que fica ainda mais evidente quando se define como objeto de estudo os "sistemas dinâmicos complexos" (MONTEIRO, 2014). A teoria da complexidade é frequentemente chamada simplesmente de "sistemas complexos", normalmente num contexto mais interdisciplinar. Um sistema complexo é um conjunto de elementos que interagem e apresentam propriedades coletivas que emergem dessa interação. O estudo dos sistemas complexos é eminentemente multidisciplinar, sendo aplicada a fenômenos físicos, químicos, biológicos, geológicos, meteorológicos, sociais e econômicos. Vários trabalhos de econofísica e sociofísica podem facilmente ser classificados como estudo de sistemas complexos, de modo a facilitar a aceitação por profissionais de outras áreas. De fato, o Instituto de Pesquisa Econômica Aplicada (IPEA) publicou um livro sobre a modelagem de sistemas complexos para políticas públicas (FURTADO; SAKOWSKI; TóVOLLI, 2015), no qual a palavra "física" aparece quarenta vezes, das quais trinta e duas ocorrências se referem claramente à física como ciência, e "econofísica" aparece outras três vezes.

A definição de sistemas complexos (ou teoria da complexidade) como um campo de estudo justifica-se pela existência de regularidades do mesmo tipo observadas em todos esses fenômenos. A Lei de Zipf, por exemplo, foi inicialmente identificada na frequência com que cada palavra aparece nos textos de um certo idioma. Posteriormente, notou-se que a lei é observada em todos os idiomas, e não somente nos idiomas, mas também na frequência de terremotos, na distribuição de riqueza entre as empresas, na distribuição de algarismos em folhas contábeis e muitos outros fenômenos. Os estatísticos já sabem há dois séculos que a distribuição normal é observada em dados dos mais variados tipos, regularidade explicada pelo Teorema do Limite Central. E muitos dados "pouco comportados", que fogem da distribuição normal, podem ser descritos por outras distribuições ou pela teoria dos fractais.

Outra área que vem recebendo muita atenção é a ciência de dados (data science). Um cientista de dados é um profissional que une conhecimento de estatística, de ciência da computação e de alguma terceira ciência da qual vem os dados analisados (comumente administração de empresas). Não existe regulamentação para essa nova profissão, de modo que a demanda por cientista de dados públicos seja suprida pelos próprios cientistas sociais que tenham conhecimento de programação de computadores. Curiosamente, a ciência de dados também tem sido considerada como um tipo de física social (PENTLAND, 2016). Esses analistas do Big Data seriam sociofísicos que estudam a sociedade a partir dos dados em direção aos modelos, por meio do reconhecimento de padrões nos dados. Essa abordagem é chamada de top-down (de cima para baixo), em oposição à abordagem bottom-up (de baixo para cima), que vai das hipóteses às conclusões por meio de simulações computacionais. Assim definida, como ciência de dados aplicada à sociedade, a sociofísica apresenta uma intersecção maior com a sociologia, havendo maior chance de colaboração, 
mas também de conflitos.

\section{CONCLUSÃo}

Podemos dizer que a definição de sociofísica e econofísica como campos de estudo é ainda vaga, pois os tipos de estudos assim classificados também aparecem praticamente da mesma forma em outros campos, tais como sociologia matemática, economia financeira, matemática aplicada, ciência de dados, teoria dos sistemas dinâmicos, teoria da complexidade, dinâmica de sistemas, teoria dos jogos etc. Se, por um lado, sociofísica e econofísica devem justificar o seu espaço em meio às áreas que compartilham seus métodos, por outro lado, precisam defender a própria legitimidade desses métodos diante de cientistas sociais aos quais o próprio termo "física" nesses contextos causa certa rejeição. Em parte, essa rejeição deve-se ao histórico de práticas discrimatórias e racistas justificadas por extrapolação de ideias das ciências naturais, frequentemente na forma de pseudociências como a frenologia e a fisiognomia. No entanto, se consequências reprováveis do passado invalidassem uma ciência, a própria antropologia teria menor legitimidade que a física. Não estaríamos correndo o risco de "jogar fora o bebê junto com a água do banho"? Deveríamos desprezar as contribuições de Francis Galton à estatística por causa de suas ideias eugênicas? Seria conveniente esquecer descobertas da medicina que tenham sido feitas em experimentos antiéticos do passado? As contribuições que permaneceram válidas foram justamente aquelas que são menos sujeitas à subjetividade. Quem, em sã consciência, sugeriria abolir conceitos estatísticos como desvio padrão, correlação e regressão por causa das ideias eugenistas de Galton e Pearson?

As objeções à sociofísica e à econofísica como campos de estudo são de natureza geral e pouco dizem sobre a validade dos estudos em si. Muitos modelos sociofísicos e econofísicos partem de hipóteses relativamente simples e por isso mesmo dificilmente refutáveis. Por exemplo, uma certa simulação da formação de hot spots de criminalidade, especificamente invasões de domicílios, partiu das seguintes hipóteses (D'ORSOGNA; PERC, 2015): em dado instante, uma pequena fração da população estaria disposta a invadir casas para subtrair algum objeto de valor (alguém duvida disso?); existem criminosos habituais (é o que dizem os dados sobre reincidência); esses potenciais invasores eventualmente caminharão pela cidade (caminhar é algo bem comum de se fazer); eles preferirão casas que tenham alguma vulnerabilidade conhecida que torne a invasão mais fácil (poderia ser diferente?); após subtrair um objeto de valor com sucesso, a pessoa fugirá daquele local (faz sentido). O resultado da simulação realizada com base nessas hipóteses é a formação de hot spots, algo bem conhecido em criminologia. O estudo não só confirma um fenômeno conhecido por criminólogos, o que poderia ser considerado óbvio, como oferece uma ferramenta para o estudo da topometria dos hot spots em relação a diferentes quantidades hipotéticas relacionadas às hipóteses: quantidade de invasores habituais, densidade de casas na cidade, mobilidade urbana etc.

Dificilmente todos os números utilizados no modelo são conhecidos e por isso várias simulações são executadas com valores hipotéticos diferentes. Nesse ponto, a colaboração com outros profissionais se faz mais desejável, porque a coleta de dados populacionais não faz parte da tradição dos físicos. As hipóteses dos modelos também poderiam ser 
refinadas por meio da referência a estudos de caso realizados por psicólogos e sociólogos. A complexidade dos fenômenos sociais e econômicos dificilmente convencerão os físicos a deixar de estudá-los, pois um tal pudor impediria de forma geral a física, na qual são corriqueiros os modelos idealizados, as aproximações e os limites de validades das teorias. Mesmo com todas essas limitações, a física é a ciência que apresenta as previsões teóricas mais acuradas já realizadas pela humanidade (SHANKAR, 1994/2011), tendo grandezas confirmadas experimentalmente em até oito algarismos significativos (uma parte em cem milhões), o que vem a mostrar que a utilidade de uma ciência não é invalidada pelo fato de haver simplificações em seus modelos.

O físico interessado em trabalhar com sociofísica e econofísica deve saber que o conhecimento de ferramentas matemáticas sofisticadas não será suficiente e que será necessário gastar algum tempo conhecendo as particularidades dos fenômenos sociais e econômicos. Deverá entender que colaborará com profissionais das ciências humanas que podem conhecer ferramentas matemáticas e estatísticas mais difundidas naquelas áreas que na física. É melhor que não tenha apego aos termos sociofísica e econofísica, pois os mesmos tipos de trabalhos são publicados sob outros rótulos. Pode ser mais adequado adotar o rótulo de "sistemas complexos", por ser um campo de estudo reconhecidamente multidisciplinar (e potencialmente interdisciplinar). A julgar pela quantidade de novos trabalhos publicados, estudos de sociofísica e econofísica parecem ser uma tendência irreversível, ainda que estejam classificados sob outros rótulos. A divisão do conhecimento entre disciplinas tem grande utilidade pedagógica, mas parece eventualmente causar certa saturação em certas linhas de pesquisa. As ciências "de fronteira", situadas entre as ciências clássicas, apresentam-se como novos campos produtivos de conhecimento.

\section{REFERÊNCIAS}

ABBAGNANO, N. Dicionário de Filosofia. Trad. 1. ed. bras. coord. e rev. por Alfredo Bosi; rev. da trad. e trad. dos novos textos por Ivone Castilho Benedetti. 2. ed. São Paulo: Martins Fontes, 2000. 42

ANTWEILER, C. Our Common Denominator. [S.l.]: Berghahn Books, 2016. 364 p. 45

APLICADA, I. de Matemática Pura e. Sistemas Dinâmicos e Teoria Ergódica. 2020. Disponível em: <https://impa.br/pesquisa/sistemas-dinamicos-e-teoria-ergodica/>. Acesso em: 3 mar. 2020. 47

AUSLOOS, M.; JOVANOVIC, F.; SCHINCKUS, C. On the 'usual' misunderstandings between econophysics and finance: Some clarifications on modelling approaches and efficient market hypothesis. 2018. Disponível em: <http://dx.doi.org/10.2139/ssrn.3294551>. Acesso em: 20 mar. 2020. 40

BEAMAN, A. L. et al. Fifteen years of foot-in-the door: A meta-analysis. Personality and Social Psychology Bulletin, v. 9, n. 2, p. 181-196. 46

BROWN, D. Human Universals. [S.1.]: McGraw Hill, 1991. 220 p. 45 
CHAKRABARTI, B. K.; CHAKRABORTI, A.; CHATTERJEE, A. Econophysics and Sociophysics: Trends and perspectives. [S.1.]: Wiley-VCH Verlag GmbH \& Co. KGaA, 2006. 33, 34, 38

CIALDINI, R. B. Influence. [S.1.]: HarperCollins e-books, 2009. 334 p. 46

COMTE, A. Considérations philosophiques sur les sciences et les savants. Producteur, p. 289-305, 348-374, 450-469, 1825. 32

COMTE, A. Social Physics: from the positive philosophy. New York: Calvin Blanchard, 1856. 31

COMTE, A. La science sociale. Paris: Éditions Gallimard, 1972. 306 p. Coletânea de artigos de Auguste Comte publicados entre 1819 e 1822. 39

D'ORSOGNA, M. R.; PERC, M. Statistical physics of crime: A review. Physics of Life Reviews, v. 12, p. 1 - 21, 2015. ISSN 1571-0645. Disponível em: <http: //www.sciencedirect.com/science/article/pii/S1571064514001730>. 48

DUROZOI, G.; ROUSSEL, A. Dicionário de Filosofia. Tradução de Marina Appenzeller. Campinas: Papiros, 1993. 42

EDLING, C. R. Mathematics in sociology. Annual Review of Sociology, v. 28, p. 197-220, 2002. Disponível em: <https://www.jstor.org/stable/3069240>. Acesso em: 2 mar. 2020. 41

FERNANDO, V. Failed economists are now developing 'econophysics' as our new savior. Business Insider, 2010. Disponível em: <https://www.businessinsider.com/ failed-economists-concoct-new-econophysics-2010-8>. Acesso em: 20 mar. 2020. 40

FREEDMAN, J. L.; FRASER, S. C. Compliance without pressure: the foot-in-the-door technique. Journal of Personality and Social Psychology, v. 4, n. 2, p. 195-202, 1996. 46

GORARD, S. Quantitative Methods in Social Science Research: The role of numbers made easy. New York: Continuum, 2003. 41

HAMADA, K. A view from an economist on econo-physics. In: TAKAYASU, H. (Ed.). The Application of Econophysics (Proceedings of the Second Nikkei Econophysics Symposium). Tóquio: Springer-Verlag, 2002. p. 310-315. 40

HARTE, J. Consider a Spherical Cow: A course in environmental problem solving. [S.l.]: University Science Books, 1991. 283 p. 43

HARTE, J. Consider a Cylindrical Cow: More adventures in environmental problem solving. [S.1.]: University Science Books, 2001. 198 p. 43

HEISENBERG, W. Física e Filosofia. Brasília: UnB, 1959/1995. 37

FURTADO, B. A.; SAKOWSKI, P. A. M.; TóVOLLI, M. H. (Ed.). Modelagem de sistemas complexos para políticas públicas. Instituto de Pesquisa Econômica Aplicada, Brasília: IPEA, 2015. 436 p. 47

JAPIASSÚ, H.; MARCONDES, D. Dicionário Básico de Filosofia. 5. ed. Edição revista e ampliada. Rio de Janeiro: Jorge Zahar Ed., 2008. 42 
KAHNEMAN, D. Maps of bounded rationality: a perspective on intuitive judgment and choice. Prize Lecture, The Nobel Prize, 2002. Disponível em: <https:/ /www.nobelprize.org/ uploads/2018/06/kahnemann-lecture.pdf>. Acesso em: 3 mar. 2020. 46

MANDELBROT, B.; HUDSON, R. L. The (mis)Behavior of Markets: A fractal view of risk, ruin, and reward. New York: Basic Books, 2004. 33

MARTIN, D.; SPINK, M. J.; PEREIRA, P. P. G. Multiple bodies, political ontologies and the logic of care: an interview with annemarie mol. Interface - Comunicação, Saúde, Educação, Botucatu, v. 22, n. 64, p. 295. Disponível em: <https://doi.org/10.1590/1807-57622017.0171>. Acesso em: 2 mar 2020. 45

MITCHELL, M. Complexity: a guided tour. [S.1.]: Oxford University Press, 2009. 366 p. 47

MONTEIRO, L. H. A. Sistemas Dinâmicos. 3. ed. São Paulo: Livraria da Física, 2011. 47

MONTEIRO, L. H. A. Sistemas Dinâmicos Complexos. 2. ed. São Paulo: Livraria da Física, 2014. 47

PENROSE, R. et al. O grande, o pequeno e a mente humana. São Paulo: Unesp \& Cambridge University Press, 1998. 37

PENTLAND, A. Social Physics: How social network can make us smarter. [S.l.]: Penguin Books, 2016. 320 p. 47

QUÉTELET, A. Du système social et des lois qui le régissent. Paris: Librairie Guillaumin et Cie (1848) / Hachette Livre BNF (2007), 1848. 32

SHANKAR, R. Principles of Quantum Mechanics. New York, London: Springer, 1994/2011. 676 p. 49

SHERMAN, L. W. et al. Evidence-based crime prevention. London, New York: Taylor \& Francis Group, 2002. 454 p. 41

SILVA, M. O. Políticas ontológicas e o problema da interdisciplinaridade entre ciências sociais e a sociofísica. Physicae Organum, p. 1-9, 2019. 39, 40, 44

SILVER, N. O sinal e o ruído: Por que tantas previsões falham e outras não. [S.1.]: Penguin Group, 2012. 534 p. 46

SOCIOPHYSICS: a personal testimony. Physica A: Statistical Mechanics and its Applications, v. 336, n. 1-2, p. 49-55, 2004. Versão gratuita: <https://arxiv.org/pdf/physics/0403122.pdf>. Disponível em: <https://www.sciencedirect.com/science/article/pii/S0378437104000329>. 31

SORNETTE, D. Why Stock Markets Crash: Critical events in complex financial systems. [S.1.]: Princeton University Press, 2017. 448 p. 46

TALACHIAN, S. Between universalism and particularism: Marx's conception of reformism in his late thought. Krisis - Journal for comtemporary philsophy, 2016. Disponível em: <https://krisis.eu/ between-universalism-and-particularism-marxs-conception-of-reformism-in-his-late-thought/ >. Acesso em: 4 mar. 2020. 46 